\title{
Sympathetic and local vasoconstrictor response to cold in vibration induced white finger
}

\author{
N OLSEN, P FJELDBORG, AND J BR $\varnothing C H N E R-M O R T E N S E N$ \\ From the Department of Clinical Physiology, Hvidovre Hospital, University of Copenhagen, Hvidovre, and \\ Department of Clinical Physiology, Aalborg Hospital, Aalborg, Denmark
}

ABSTRACT To study the relative roles of sympathetic and local vasoconstrictor response to cold in vibration induced white finger (VWF) seven lumberjacks with bilateral VWF and seven age matched controls were investigated. During body cooling finger systolic blood pressure was measured with a cuff technique simultaneously on one affected finger on each hand at $30^{\circ}, 15^{\circ}$, and $6^{\circ} \mathrm{C}$. Both affected fingers had an increased vasoconstrictor response at $15^{\circ}$ and $6^{\circ} \mathrm{C}$ compared with the control group $(p \leqslant 0.05)$. During unilateral sympathetic nerve block the cold provocation test was repeated on both fingers. The unblocked finger affected by VWF showed no significant difference in the cold response between the two cold provocation tests $(p>0 \cdot 10)$. The local cold response of blocked finger did not differ from that of the control group $(p>0 \cdot 10)$. The sympathetic vasoconstrictor response to cold was estimated as the difference between the cold response before nerve block and the cold response during nerve block. The median sympathetic vasoconstrictor response at $6^{\circ} \mathrm{C}$ was about twice as large as the local response during nerve block $(p<0.05)$. The results indicate that the sympathetic vasoconstrictor response to cold plays the dominant part in VWF.

Raynaud's phenomenon is characterised by episodic digital ischaemia provoked by stimuli such as cold and emotion. The nature of the circulatory disturbance is still the subject of controversy.' Raynaud's original proposal ${ }^{2}$ of hyperactivity of the sympathetic nervous system and the later assertion by Lewis ${ }^{34}$ of a "local digital vascular fault" independent of the nervous system constitute the classic pathophysiological theories for Raynaud's phenomenon. Furthermore, the pathophysiology is unknown in vibration induced white finger (VWF), ${ }^{5}$ which is a secondary form of Raynaud's phenomenon caused by vibrating hand tools. The aim of the present study was to investigate the relative roles of the sympathetic vasoconstrictor system and local factors respectively in the aetiology of VWF. For that purpose a group of lumberjacks with bilateral VWF were studied before and during unilateral sympathetic nerve block by the use of a method in which the systolic blood pressure in the finger was measured after body and digital cooling. ${ }^{6}$ The cold responses were compared with those of a control group.

Received 2 July 1984

Accepted 30 July 1984

\section{Subjects and methods}

Seven lumberjacks and seven controls took part in the investigation. All had given written informed consent, and the study had been approved by the local ethical committee.

Recently we had investigated a subsample of 39 lumberjacks who were representative of 365 lumberjacks. ${ }^{7}$ In the subsample eight subjects were bilaterally affected by VWF. Five years later one lumberjack had not observed attacks of white fingers for two years, and so was excluded. The remaining seven lumberjacks still had bilateral VWF as evaluated by a medical interview. The stages of VWF were based on a medical interview as described by Taylor and Pelmear ${ }^{8}$ and Chatterjee et $a^{4}$.

Stage 1-blanching of one or more fingertips.

Stage 2-blanching characterised by increased frequency of attacks and number of fingers affected without interference with work.

Stage 3-extensive blanching with frequent episodes during summer and winter and with definite interference with work.

Stage 4-extensive blanching of all digits during 
Table 1 Characteristics of seven lumberjacks and seven controls. Values are given as numbers or as the median with the range in brackets

\begin{tabular}{lcl}
\hline & Lumberjacks & Control group \\
\hline Age (years) & $61(54-73)$ & $59(50-63)$ \\
Smokers (No) & 5 & 5 \\
Tobacco/day (g) & $27(20-30)$ & $20(13-30)$ \\
Use of gloves (No) & 5 & \\
Exposure period (years) & $20(11-25)$ \\
Duration of VWF (years) & $10(8-21)$ \\
Latent period (years) & $5(0-15)$ \\
Stages 1, 2, 3, 4, (No) & $0,3,4,0$ \\
Fingers affected by VWF: & $4(2-4)$ \\
Right hand (No) & $3(2-4)$ \\
Left hand (No) & $6(4-8)$ \\
Both hands (No) & \\
\hline
\end{tabular}

No significant difference control group and lumberjacks $(p>0 \cdot 10)$.

summer and winter, leading to a change of occupation.

Table 1 gives the characteristics of the seven lumberjacks. Seven controls were selected according to the following criteria, confirmed from a medical interview: outdoor working man, never worked with vibrating hand tools, without primary finger symptoms, no causes of Raynaud's phenomenon, and no vascular or metabolic disorders. The controls and the lumberjacks did not differ significantly in age distribution or smoking habits (table 1).

The subjects were investigated in supine position after 10 minutes of rest with their fingers at the level of the heart and dressed in indoor clothing. The room temperature was $19^{\circ} \mathrm{C}$. Body cooling was performed by a cooling blanket perfused continuously with water at $8-12^{\circ} \mathrm{C} 10$ minutes before and during the investigation. Only fingers with no history of trauma were investigated. In subjects with VWF the finger on each hand most frequently showing Raynaud's attack according to the medical interview was simultaneously cold provoked and the nonaffected thumbs were used for reference. In the controls only the middle finger of one hand was cold provoked with the thumb as a reference. Finger cooling was performed using a double inlet cuff on the midphalanx during five minute ischaemia produced with an occluding cuff on the proximal phalanx. ${ }^{6}$ Finger systolic blood pressure (FSP) was measured with a strain gauge technique ${ }^{10}$ after cooling to $30^{\circ}, 15^{\circ}$, and $6^{\circ} \mathrm{C}$ (for further details see Olsen and Nielsen"). The results were expressed as the decrease $(R(x))$ in FSP $\left(F^{2} P_{x}\right)$ at the cooling temperature $(x)$ relative to the pressure of the identical finger at $30^{\circ} \mathrm{C}$. The last mentioned was corrected for fluctuations in arterial pressure during the period of measurement by subtracting the FSP difference at the uncooled thumb, measured at the time of measurement at $30^{\circ} \mathrm{C}$ and $x^{\circ} \mathrm{C}$ respectively ( SSP $\left._{30}^{\text {corr }}\right)$. The results were expressed as per cent:

$$
R(x)=\stackrel{\left(1-\text { FSP }_{x}\right)}{\text { FSP }_{30}^{c o r r}} \cdot 100
$$

Arm blood pressure was measured by auscultation with a $12 \mathrm{~cm}$ broad cuff on both upper arms.

After the first cooling test at $30^{\circ}, 15^{\circ}$, and $6^{\circ} \mathrm{C}$ sympathetic nerve block of the finger most often affected by VWF was performed with a conventional digital block. ${ }^{12}$ At the base of the finger, $1 \mathrm{ml}$ of $2 \%$ lignocaine was injected close to each of the four digital nerves, making a total volume of $4 \mathrm{ml}$. A neurological assessment was made 10 minutes later and during the cold provocation test. The small nerve fibres including the sympathetic fibres were considered as blocked when the subject could not feel pinprick and cold. Within 60 minutes of the nerves being blocked, a second cold provocation test was completed in a similar manner. In all the lumberjacks the blockade was sufficient during the investigation. The thermostated finger on the contralateral hand was unblocked. No blockade was performed in the control group. Raynaud's phenomenon with digital arterial closure as defined by Lewis ${ }^{3}$ was verified by the presence of a zero pressure in the finger at $15^{\circ}$ or $6^{\circ} \mathrm{C}(\mathrm{R}(\mathrm{x})=100 \%)$. The sympathetic vasoconstrictor response (S) to cold was estimated as the difference between the total cold pressure (T) before nerve block and the local cold response (L) during nerve block.

Statistical evaluation was performed by nonparametric statistics with a significance limit of 0.05 (two-sided). The difference in numerical measurements between two related samples and between two independent samples was tested with the Wilcoxon matched pairs signed rank test and the Mann-Whitney rank sum test. Normal $95 \%$ confidence limits were calculated from the $t$ distribution.

\section{Results}

Table 2 gives the systolic blood pressures at $30^{\circ} \mathrm{C}$. Among the lumberjacks, there was no significant difference in the $\mathrm{FSP}_{30}$ on either thermostated finger, blocked or unblocked. Furthermore, only one lumberjack had an increased pressure gradient from the upper arm to the finger, the upper normal $95 \%$ confidence limit being $35 \mathrm{~mm} \mathrm{Hg}$. The results of the cold provocation tests are compared in table 3 . In the control group the $R(x)$ increased when the finger was cooled from $30^{\circ}$ to $15^{\circ} \mathrm{C}$ and from $15^{\circ}$ to $6^{\circ} \mathrm{C}(\mathrm{p}=0.02)$. The upper normal $95 \%$ confidence limits of $R(x)$ were $21 \%$ at $15^{\circ} \mathrm{C}$ and $48 \%$ at $6^{\circ} \mathrm{C}$. A zero pressure was shown in all four lumberjacks in stage 3 before blockade, in none of the lumberjacks 
Table 2 Systolic blood pressure in the upper arm (ASP) and the thermostated finger at $30^{\circ} \mathrm{C}\left(F \mathrm{FP}_{30}\right)$ on the side (B) where nerve block was performed and on the contralateral side $(C)$. Values are given as the median (range)

\begin{tabular}{|c|c|c|c|c|}
\hline & \multirow{2}{*}{$\begin{array}{l}\text { Systolic pressure } \\
\left.\text { ( } \mathrm{mm} \mathrm{Hg}_{\mathrm{g}}\right)\end{array}$} & \multirow{2}{*}{$\begin{array}{l}\text { Control group } \\
(n=7)\end{array}$} & \multicolumn{2}{|c|}{ Lumberjacks with VWF } \\
\hline & & & $\begin{array}{l}C \text {-side } \\
(n=7)\end{array}$ & $\begin{array}{l}\text { B-side } \\
(n=7)\end{array}$ \\
\hline $\begin{array}{l}\text { Before nerve block } \\
\text { During unilateral nerve block }\end{array}$ & $\begin{array}{l}\text { ASP } \\
\text { FSP }^{30} \\
\text { ASP-FSP }_{30} \\
\text { ASP } \\
\text { FSP }_{30} \\
\text { ASP-FSP }_{30}\end{array}$ & $\begin{array}{l}155(130-175) \\
140(110-165) \\
15(10-30)\end{array}$ & $\begin{array}{c}130(120-200) \\
125(110-195) \\
5(-5 \text { to } 10)^{*} \\
135(110-210) \\
115(90-185) \\
20(5-25) \dagger\end{array}$ & $\begin{array}{c}125(120-200) \\
130(120-160) \\
0(-10 \text { to } 40) \\
130(110-190) \\
110(90-135) \\
25(5-70) \dagger\end{array}$ \\
\hline
\end{tabular}

No significant difference between C-side and B-side $(p>0.05)$.

*Significant from control group ( $p<0.05)$.

tSignificant from value before nerve block $(p<0.05)$.

The change in arm finger pressure gradient did not differ significantly between C-side and B-side ( $p>0.05)$.

Table 3 Relative decrease in finger systolic blood pressure by finger cooling to $15^{\circ}$ and $6^{\circ} \mathrm{C}$ from $30^{\circ} \mathrm{C}$, measured as the percentage of the pressure at $30^{\circ} \mathrm{C}$ : on the side $(B)$ where nerve block was performed and on the contralateral side $(C)$.

Values are given as the median (range)

\begin{tabular}{|c|c|c|c|c|}
\hline & \multirow{2}{*}{$\begin{array}{l}\text { Finger temperature } \\
{ }^{\circ} \mathrm{C}\end{array}$} & \multirow{2}{*}{$\begin{array}{l}\text { Control group } \\
(n=7)\end{array}$} & \multicolumn{2}{|c|}{ Lumberjacks with VWF } \\
\hline & & & $\begin{array}{l}\text { C-side } \\
(n=7)\end{array}$ & $\begin{array}{l}\text { B-side } \\
(n=7)\end{array}$ \\
\hline $\begin{array}{l}\text { Before nerve block (a) } \\
\text { During unilateral nerve block (b) } \\
\text { Difference (a-b) }\end{array}$ & $\begin{array}{r}15 \\
6 \\
15 \\
6 \\
15 \\
6\end{array}$ & $\begin{array}{c}9(3-17) \\
25(12-35)\end{array}$ & $\begin{array}{l}18(12-100)^{*} \\
57(25-100)^{*} \\
17(0-100)^{n} \\
55(17-100)^{*} \\
5(0-19)^{n} \\
8(-6 \text { to } 45) \ddagger\end{array}$ & $\begin{array}{c}25(12-100)^{*} \\
100(50-100)^{*} \\
5(0-17)^{n} \\
27(21-45) \\
12(4-97)^{n} \dagger \\
55(24-76)^{*} \dagger \ddagger\end{array}$ \\
\hline
\end{tabular}

*Significant from control group at same temperature $(p \leqslant 0.05)$.

tSignificant difference $(a-b)(p \leqslant 0.05)$.

$\ddagger$ Difference $(a-b)$ significant from value $(b)(p<0.05)$.

$\mathrm{n}=6$.

in stage 2 , and in none of the controls. The main results in table 3 concern the nerve blocked finger and are shown in the figure. Compared with the con-

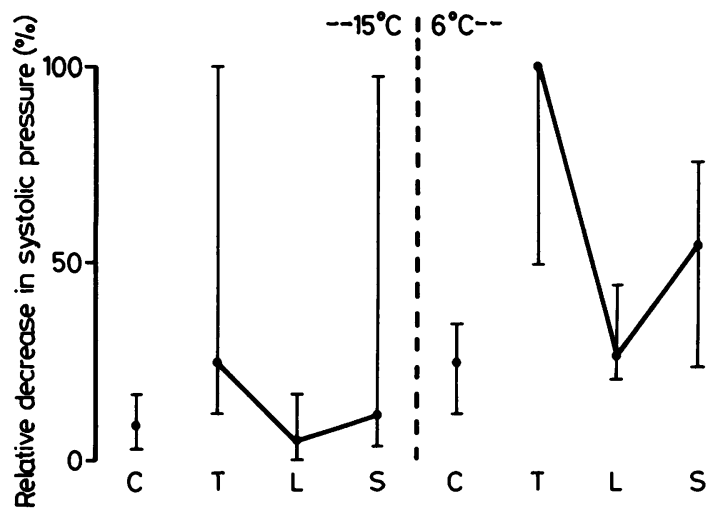

Relative decrease in finger systolic blood pressure by finger cooling to $15^{\circ}$ and $6^{\circ} \mathrm{C}$ from $30^{\circ} \mathrm{C}$, measured as percentage of pressure at $30^{\circ} \mathrm{C}$ in seven controls $(C)$ and in seven lumberjacks with $V W F$ before nerve block $(T)$ and during nerve block (L). Sympathetic vasoconstrictor response (S) to cold was estimated as difference between total cold response $(T)$ and local cold response $(L)$. Values are given as median and range. trol group, the cold response was significantly increased before nerve block $(p<0.01)$ but there was no difference during nerve block $(p>0 \cdot 10)$. The sympathetic vasoconstrictor response at $6^{\circ} \mathrm{C}$ was about twice as large as the local response, expressed as median values $(p<0.05)$. The cold response of the contralateral, unblocked finger did not differ between the two measurements ( $p>$ $0 \cdot 10)$.

\section{Discussion}

In the present study the unilateral injection of lignocaine at the base of the finger did not significantly change the $\mathrm{FSP}_{30}$ on the midphalanx or the arm finger pressure gradient as compared with the gradient on the contralateral side. These findings indicate that the sympathetic blockade did not influence the measurements at $30^{\circ}$. The unblocked finger affected by VWF showed no significant difference in the cold response between the two cooling tests. This indicates that no weakening of the vasoconstrictor response took place during the investigation.? At $30^{\circ} \mathrm{C}$ the arm finger pressure gradients were within the normal $95 \%$ confidence limits in six lumberjacks, no systolic blood pressures in the affected 
fingers were below $90 \mathrm{~mm} \mathrm{Hg}$, and no affected fingers had ischaemic signs at this temperature as evaluated by visual inspection. These findings suggest that no significant obstruction of the digital arteries could be shown in six of the seven lumberjacks. ${ }^{13}$ The main results of the present study showed that before nerve block, the affected finger had a significantly increased vasoconstrictor response to cold and during nerve block had a cold response that did not differ from that in the control group. The sympathetic vasoconstrictor response to cold at $6^{\circ} \mathrm{C}$ was significantly increased compared with the local response and, expressed as a median value, about twice as large as the local response. With the use of the same method, we have shown earlier that in subjects with primary Raynaud's phenomenon the sympathetic vasoconstrictor response to cold was also the dominant factor. ${ }^{14}$ With the use of a calorimetric method Greenfield et al found that, after following digital cooling in normal subjects, vasoconstriction was absent or less complete on the side with nerve block than on the control finger. ${ }^{15}$ Raynaud found that the digital blood vessels in Raynaud's disease were normal and presumed that the vessels went into spasm due to hyperactivity in the sympathetic nervous system. ${ }^{2}$ By contrast Lewis and Pickering found evidence from physiological and pathological studies, including a case of VWF, that Raynaud's phenomenon was caused by a "local fault" in the digital arteries regardless of the nervous system. ${ }^{16} 17$ Lewis further found that complete anaesthetisation of the ulnar nerve did not prevent the vessels of the fifth fingers from being subsequently thrown into a complete obstructive spasm by the local application of cold. ${ }^{3} \mathrm{He}$ also considered that the tone in the digital arteries, when in spasm, was derived from two sources, the exaggerated effect of temperature acting locally and the normal sympathetic vasoconstrictor tone. His conclusions contrast with the results of the present study, perhaps because different types of patient were studied.

The main conclusion of the present study is that the local vasoconstrictor response to cold plays only a minor part in VWF compared with the dominant sympathetic vasoconstrictor response to cold. This may be explained theoretically by hyperactivity of the $\alpha$-adrenergic sympathetic nervous system, ${ }^{2}$ a relative lack of $\beta$-adrenergic sensitivity of the cutaneous vessels, ${ }^{18}$ a hyperresponsiveness of the digital smooth muscles to normal nervous stimuli, ${ }^{19}$ a muscular hypertrophy of the digital arterial wall, ${ }^{20}$ or a combination of all these mechanisms.
We thank all the workers and employers who took part in the study.

Requests for reprints to: Niels Olsen, Frydendalsvej

1, DK-1809 Copenhagen V, Denmark.

\section{References}

'Anonymous. Pathophysiology of Raynaud's phenomenon [Editorial]. Br Med J 1980;281:1027-8.

${ }^{2}$ Raynaud M. De l'asphyxie locale et de la gangrène symetrique des extrémites. Paris: Rignoux, 1862.

${ }^{3}$ Lewis $T$. Experiments relating to the peripheral mechanism involved in spasmodic arrest of the circulation in the fingers. A variety of Raynaud's disease. Heart 1929;15:7-101.

4 Lewis T, Landis EM. Observations upon the vascular mechanism in acrocyanosis. Heart 1930;15:229-46.

${ }^{5}$ Anonymous. Vibration syndrome again [Editorial]. $\mathrm{Br} \mathrm{Med} J$ 1981;282:1738-9.

- Nielsen SL, Lassen NA. Measurement of digital blood pressure after local cooling. J Appl Physiol 1977;43:907-10.

' Olsen N, Nielsen SL, Voss P. Cold response of digital arteries in chain saw operators. Br J Ind Med 1982;39:82-8.

${ }^{8}$ Taylor W, Pelmear PL. Vibration white finger in industry. London: Academic Press, 1975:xvii-xxii.

${ }^{9}$ Chatterjee DS, Petri A, Taylor W. Prevalence of vibrationinduced white finger in fluorspar mines in Weardale. $\mathrm{Br} \mathrm{J}$ Ind Med 1978;35:208-18.

${ }^{10}$ Hirai M, Nielsen SL, Lassen NA. Blood pressure measurements of all five fingers by strain gauge plethysmography. Scand $J$ Clin Lab Invest 1976;36:627-32.

"Olsen N, Nielsen SL. Diagnosis of Raynaud's phenomenon in quarrymen's traumatic vasospastic disease. Scand J Work Environ Health 1979;5:249-56.

${ }^{12}$ Moore DC. Regional block. 4th ed. Springfield: Charles C Thomas, 1975:304-6.

${ }^{13}$ Hirai MH. Arterial insufficiency of the hand evaluated by digital blood pressure and arteriographic findings. Circulation 1978; 58:902-8.

${ }^{14}$ Nielsen SL, Olsen N, Henriksen O. Cold hypersensitivity after sympathectomy for Raynaud's disease. Scand J Thorac Cardiovasc Surg 1980;14:109-11.

is Greenfield ADM, Shepherd JT, Whelan RF. The part played by the nervous system in the response to cold of the circulation through the finger tip. Clin Sci 1951;10:347-60.

${ }^{16}$ Lewis T, Pickering GW. Observations upon maladies in which the blood supply to digits ceases intermittently or permanently, and upon bilateral gangrene of digits; observations relevant to so-called "Raynaud's disease." Clin Sci $1934 ; 1: 327-66$.

${ }^{17}$ Lewis $T$. The pathological changes in the arteries supplying the fingers in warm-handed people and in cases of so-called Raynaud's disease. Clin Sci 1938;3:287-319.

${ }^{18}$ Thune P, Fyrand O. Further observations on the therapy with a beta-stimulating agent in Raynaud's phenomenon. Acta Chir Scand 1976;suppl465:84-6.

19 Azuma T, Ohhashi T, Sakaguchi M. Vibration-induced hyperresponsiveness of arterial smooth muscle to noradrenaline with special reference to Raynaud's phenomenon in vibration disease. Cardiovasc Res 1978;12:758-64.

${ }^{20}$ Hyvărinen J, Pyykkö I, Sundberg S. Vibration frequencies and amplitudes in the aetiology of traumatic vasospastic disease. Lancet 1973; i: 791-4. 